\title{
Challenges of population ageing: putting frailty as a cornerstone of health and social care systems
}

\author{
Jean Woo ${ }^{1}$ \\ Received: 13 April 2018 / Accepted: 18 April 2018 / Published online: 27 April 2018 \\ (c) European Geriatric Medicine Society 2018
}

\section{Historical perspectives}

Geriatric medicine as a specialty has a fairly short history, its establishment resting on the efforts of prominent UK doctors initially. The core of geriatric medicine is the multi-domain approach that covers physical, functional, psychological, nutritional, and social domains versus the system approach, embodied by the comprehensive geriatric assessment. The dissemination of this specialty to other countries depended much on continuing advocacy by doctors who received training from established geriatric departments and then incorporating the specialty into the training curriculum and service delivery models of their own countries. Such efforts have varying degrees of success, and the specialty has seldom achieved the same status as other organ-based specialty such as cardiology or gastroenterology, being reflected by fewer (and declining) number of trainees. Neither has this approach been adopted widely in the primary care setting [1]. Worldwide there are various reasons for this such as: the observations that there are nothing special and everyone looks after elderly patients; attractions to specialties involving advanced technologies and procedures; negative images of ageing and lower health care prioritizations; and lower professional income or status. One major obstacle is that it is difficult to explain the need for this specialty in a concise way. The concept of frailty that has been developing in the past 20 years represents a unique opportunity to describe the essence of geriatric medicine in a concise, quantifiable, and measurable way that can be understood by clinicians, health managers, and policy makers.

Jean Woo

jeanwoowong@cuhk.edu.hk

1 Department of Medicine and Therapeutics, Faculty of Medicine, The Chinese University of Hong Kong, Sha Tin, Hong Kong

\section{Frailty research and its impact}

To date, the body of research has established that frailty represents a phenotype that is increasingly prevalent among older people ( $25 \%$ of $85+$ years); that predicts many adverse outcomes better than individual indicators; that is not disability or multi-morbidity, but closely related; that has a biological basis in multi-system dysregulation resulting in failure of homeostasis, having the characteristics of complex dynamic non-linear systems when stressed by external factors; and also representing a clinical syndrome where screening, diagnosis, prognosis, prevention, treatment, and uptake by health systems apply [2]. Frailty as an entity forms the topic of research from genomics [3], to 'frailomics' [4], to urban design [5].

\section{Relevance to public health, health policy, and clinical management}

From the public health perspective, frailty may be used as an indicator of service utilization [6], as well as an indicator of whether populations are ageing well. An indicator of frailty would be more relevant to ageing populations as an indicator of ageing well, and indirectly the magnitude of health and social care burden resulting from increasing numbers of very old people, and represent an advancement over the traditional indicators such as mortality (life span indicator only) and disability, consequent to chronic diseases (disability only). Relevant public health statistics should include trends in disability as well as frailty, to allow projections and formulation of health and social care policies in response to population ageing [7-9]. The inclusion of frailty is important as it captures a vulnerable state which may be prevented or ameliorated through lifestyle modification in mid-life, as well as risk-factor modification that includes the physical and social environment $[5,10]$. 
From the health promotion perspective, frailty may be prevented or its onset retarded by nutrition and physical activity [11-13]. The frailty phenotype may be detected in community screening using a simplified questionnaire without the need for measurements or administration by specialist healthcare personnel, incorporated as a part of general practice routine assessment, or part of the health and social needs assessment $[14,15]$. Intervention strategies are also in place, recent guidelines being recently promoted in the Asia-Pacific region for the management of frailty [16].

There are also increasing numbers of publications describing the role of frailty assessment in investigation and management of diseases in various specialties such as oncology, cardiology, and nephrology [17-19]. Frailty screening has also been described in Accident and Emergency Departments [20-22]. These developments are encouraging and provide momentum in re-designing fit-for-purpose health and social services to meet the needs of ageing populations [23].

\section{Role of geriatricians as advocates in promoting this agenda}

Geriatricians should function as advocates in promoting this agenda, by leading health services research in models of service delivery incorporating frailty assessment, as well as participate in re-shaping services for older people. In view of the increasing demand for hospital and primary care services from rapid population ageing, with a likely trend in increasing frailty and disability, geriatricians have a key role in helping shape frailty-oriented health policy and service delivery models. A good example is the case of Singapore, where geriatricians play a prominent role in working with health ministers to formulate 'frailty-ready' health policies, with screening and intervention taking place in the setting of community centres $[16,24]$. Another example is the introduction of an automated rapid geriatric screening system with suggested investigation and management that has been introduced to family medicine doctors in St Louis, MO, USA [25].

Yet another example is the recent development in Hong Kong, a Special Administrative Region of China, which currently has the longest life expectancy in the world for both men and women. The government has recently commissioned a review of elderly services, together with new models of service delivery to meet the needs of population ageing. The essence of the recommendations has been reported in a policy report by a prominent think-tank advising the government. Frailty as an entity was included, together with health-enabling networks integrating health and social components to promote healthy ageing [26], as well as frailty screening at the Accident and Emergency
Departments. A major charitable foundation is also supporting a territory-wide model of primary care which includes screening of frailty and other geriatric syndromes in addition to blood pressure, glucose, and body mass index, based on the widespread existing network of elderly centres run by non-government organizations with data captured by smart devices and dealt with at a central point using big data technology (www.ioa.cuhk/en-gb/training/jockey-club-commu nity-ehealth-care-project).

\section{Diversions from recent research and public health discourse}

However, this momentum may be in danger of being diverted by the lack of universal consensus on how to assess or measure frailty, promotion and research in related concepts in recent years. These factors affect the incorporation of frailty considerations into routine clinical management, design of health and social services, funding allocations, and formulation of health policies.

Assessment of frailty has been dominated by two apparently different approaches, the phenotypic versus the multiple deficit model [27]. Adoption of the phenotypic definition may be easier in the clinical setting, while the multiple deficit approach may be more appropriate for population research purposes since time and costs for measurements and investigations would be important factors for adoption into clinical management systems. The technological advances in automated data capturing may overcome these obstacles.

With the proliferation of frailty as a topic in ageing research, as shown by the numerous sessions and papers presented at the 2017 International Association of Gerontology and Geriatrics in San Francisco, USA, new entities are being featured such as social frailty, cognitive frailty [28], and psychological frailty. It may be argued that some are the risk factors for frailty, which represents an intrinsic property in the same way that high salt intake gives rise to hypertension. However, for health and social care professionals involved in providing direct service to older people who are being introduced to frailty as an entity that is preventable, reversible, and detectable, confusion results. At the same time, different groups continue to propose descriptors of ageing populations that includes the word 'frailty', although the concepts are similar to other more widely used instruments [29-31]. From social science researchers, there is also an opinion that the term frailty may be stigmatising and not acceptable by older people themselves [32].

The World Health Organization's response to ageing populations resulted in several reports: the promotion of the Age-Friendly City concept (www.who.int/ageing/agefriendly-environments/en/); the Healthy Ageing Report 
(www.who.int/ageing/publications/world-report-2015/en/), the Integrated Care of Older people (www.who.int/ageing/ publications/guidelines-icope/en/), the use of mobile technology in primary care, or mAgeing [33], and the introduction of the term 'intrinsic capacity' to emphasize the life course approach. A common theme to all is function as a main outcome, with discussions on what indicator(s) may be used. There are also efforts to 'map' frailty components into the International Classification of Function Disability and Health framework (body structure, body function, activity, and participation) (www.who.int/classifications/icf/en/).

The National Institute of Health has highlighted another related area for funding: resilience, which may be applied to cellular components, psychosocial, physical, and the community. At its core is function and response to stressors. There is an overlap with the frailty phenotype definition and concept [34-36].

\section{The way forward}

It is extremely encouraging to see the proliferation of research agenda on frailty and related concepts, as a key accompaniment of population ageing. However, there is a need to develop parallel service research with health service models and economic evaluations, and the inclusion of frailty into clinical management protocols, and as a summary health outcome when examining physical- and social-environmental health impacts for older people. Only with such data can frailty be established as a 'real' and very relevant concept for ageing population and older people in the service sector, rather than a fashionable topic of research.

\section{Compliance with ethical standards}

Conflict of interest The author declares that she has no conflict of interest.

Ethical approval This article does not contain any studies with human participants or animals performed by any of the authors.

Informed consent For this type of study formal consent is not required.

\section{References}

1. Garrard JW, Dodds RM, Lansbury L, Cox N, Roberts HC, Aihie Sayer A (2018) The implementation of comprehensive geriatric assessment in primary care: initial finding from a systematic review. Age Ageing 47:ii1

2. Fougère $B$ (2018) Linda fried ICFSR life achievement award: the 12 major advances in the field of frailty. International conference on frailty and sarcopenia research (Press release). http://www. aging-news.net/wpcontent/uploads/2018/03/Press-release-ICFSR $-2018-n \%$ C2\%B0-2.pdf
3. Verdi S, Cheesman R, Bowyer RCE, Mangino M, Spector TD, Steves CJ (2018) A genome wide association study identifying a genetic variant for frailty using the TWINSUK cohort. Age Ageing 47:ii 15-ii18

4. Rodriguez-Manas L (2017) Contribution of the frailomic initiative to the biological understanding of frailty and resilience. Innov Aging 1(S1):665

5. Yu R, Wang D, Leung J, Lau K, Kwok T, Woo J (2018) Is neighborhood green space associated with less frailty? Evidence from the Mr. and Ms. Os (Hong Kong) study. J Am Med Dir Assoc (in press). https://doi.org/10.1016/j.jamda.2017.12.015

6. Woo J, Goggins W, Sham A, Ho SC (2006) Public health significance of the frailty index. Disabil Rehabil 28(8):515-521

7. Yu R, Wong M, Chang B, Lai X, Lum CM, Auyeung TW et al (2016) Trends in activities of daily living disability in a large sample of community-dwelling Chinese older adults in Hong Kong: an age-period-cohort analysis. BMJ Open 6(12):e013259

8. Yu R, Wong M, Chong KC, Chang B, Lum CM, Auyeung TW et al (2018) Trajectories of frailty among Chinese older people in Hong Kong between 2001 and 2012: an age-period-cohort analysis. Age Ageing 47(2):254-261

9. Cesari M, Prince M, Thiyagarajan JA, De Carvalho IA, Bernabei R, Chan P et al (2016) Frailty: an emerging public health priority. J Am Med Dir Assoc 17(3):188-192

10. Yu R, Wu WC, Leung J, Hu SC, Woo J (2017) Frailty and its contributory factors in older adults: a comparison of two Asian Regions (Hong Kong and Taiwan). Int J Environ Res Public Health 14(10): 1096

11. Shinkai S, Yoshida H, Taniguchi Y, Murayama H, Nishi M, Amano $\mathrm{H}$ et al (2016) Public health approach to preventing frailty in the community and its effect on healthy aging in Japan. Geriatr Gerontol Int 16:87-97

12. Michel JP, Cruz-Jentoft AJ, Cederholm T (2015) Frailty, exercise and nutrition. Clin Liver Dis 19(3):375-387

13. Lozano-Montoya I, Correa-Perez A, Abraha I, Soiza RL, Cherubini A, O'Mahony D et al (2017) Nonpharmacological interventions to treat physical frailty and sarcopenia in older patients: a systematic overview-the SENATOR Project ONTOP series. Clin Interv Aging 12:721-740

14. Strandberg TE, Pitkala KH, Tilvis RS (2011) Frailty in older people. Eur Geriatr Med 2(6):344-355

15. Morley JE, Arai H, Cao L, Dong B, Merchant RA, Vellas B et al (2017) Integrated care: enhancing the role of the primary health care professional in preventing functional decline: a systematic review. J Am Med Dir Assoc 18(6):489-494

16. Dent E, Lien C, Lim WS, Wong WC, Wong CH, Ng TP et al (2017) The Asia-Pacific clinical practice guidelines for the management of frailty. J Am Med Dir Assoc. 18(7):564-575

17. Hubbard JM, Jatoi A (2015) Incorporating biomarkers of frailty and senescence in cancer therapeutic trials. J Gerontol Biol 70(6):722-728

18. Kim DH, Kim CA, Placide S, Lipsitz LA, Marcantonio ER (2016) Preoperative frailty assessment and outcomes at 6 months or later in older adults undergoing cardiac surgical procedures a systematic review. Ann Intern Med 165(9):650-660

19. Kallenberg MH, Kleinveld HA, Dekker FW, van Munster BC, Rabelink TJ, van Buren M et al (2016) Functional and cognitive impairment, frailty, and adverse health outcomes in older patients reaching ESRD-a systematic review. Clin J Am Soc Nephrol 11(9):1624-1639

20. Jay S, Whittaker P, McIntosh J, Hadden N (2017) Can consultant geriatrician led comprehensive geriatric assessment in the emergency department reduce hospital admission rates? A systematic review. Age Ageing 46(3):366-372 
21. Hassim K, Briggs S (2018) Identifying frailty at the front dooran audit into the success of the introduction of a frailty score into an emergency department. Age Ageing 47:ii25-ii39

22. Martin-Marero C, Rolph G, Dineros C, Jobsz N, Farrant C, Lethby M et al (2018) Successful specialist intervention of older people with frailty at the front door at West Middlesex University Hospital: improving patients outcomes. Age Ageing 47:ii25-ii39

23. Woo J (2017) Designing fit for purpose health and social services for ageing populations. Int J Environ Res Public Health 14(5):457

24. Lim WS, Wong SF, Leong I, Choo P, Pang WS (2017) Forging a frailty-ready healthcare system to meet population ageing. Int $\mathrm{J}$ Environ Res Public Health 14(12): 1448

25. Morley JE, Adams EV (2015) Rapid geriatric assessment. J Am Med Dir Assoc 16(10):808-812

26. Yeoh EK, Lai AHY (2016) An investment for the celebration of aging. Hong Kong: Our Hong Kong Foundation. http://ourhk foundation.org.hk/en/node/1215

27. Buta BJ, Walston JD, Godino JG, Park M, Kalyani RR, Xue QL et al (2016) Frailty assessment instruments: systematic characterization of the uses and contexts of highly cited instruments. Ageing Res Rev 26:53-61

28. Morley JE (2015) Cognitive frailty: a new geriatric syndrome? Eur Geriatr Med 6(5):408-411
29. Ng TP, Feng L, Nyunt MS, Larbi A, Yap KB (2014) Frailty in older persons: multisystem risk factors and the Frailty Risk Index (FRI). J Am Med Dir Assoc 15(9):635-642

30. Kwan JS, Lau BH, Cheung KS (2015) Toward a comprehensive model of frailty: an emerging concept from the Hong Kong Centenarian Study. J Am Med Dir Assoc 16(6):536 e1-7

31. Hippisley-Cox J, Coupland C (2017) Development and validation of QMortality risk prediction algorithm to estimate short term risk of death and assess frailty: cohort study. BMJ Br Med J 358:j4208

32. Nicholson C, Gordon AL, Tinker A (2017) Changing the way "we" view and talk about frailty. Age Ageing 46(3):349-351

33. WHO (2018) Be healthy, be mobile-a handbook on how to implement mAgeing. Geneva World Health Organization (in press). http://www.who.int/ncds/prevention/be-healthy-be-mobil e/handbooks/en/

34. Cohen HJ (ed) (2017) Defining and understanding resilience. Keynote lecture. In: 8th Association of Pacific Rim research universities conference on population ageing, 11 October 2017, Singapore

35. Walston JD (2017) Conceptualizing frailty and resilience and their physiological basis. Innov Aging 1(S1):664

36. Rockwood K, Mitnitski A (2015) Resilience and frailty: further steps, best taken together. Eur Geriatr Med 6(5):405-407 